\title{
Error Analysis on the Use of Reference Devices in Argumentative and Descriptive Writings of Yemeni EFL Learners at the University of Aden: A Comparative Case Study
}

\author{
Aref Nassi Abduh Nasser \\ Assistant Professor, Department of English, Faculty of Education-Lowder, University of Abyan, \\ Republic of Yemen \\ arefnassi1980@gmail.com
}

DOI: https://doi.org/10.36892/ijlls.v2i1.190

$\begin{array}{ll}\begin{array}{l}\text { Received: } \\ \text { 12/1/2020 }\end{array} & \text { Abstract } \\ \text { Accepted: } & \text { This paper is an attempt to analyze errors in the use of reference devices in } \\ \text { 12/3/2020 } & \text { University of Aden. It particularly aimed at making a comparison between } \\ & \text { errors in the use of these devices in the argumentative genre and those in } \\ & \text { the descriptive genre as committed by Yemeni learners of English as a } \\ \text { Keywords: } & \text { foreign language. It particularly relied on the methodology of error } \\ \text { Argumentative texts, } & \text { analysis. The sample of the study was eighteen students (n=18) of the third } \\ \text { Descriptive Texts, } & \text { level in the Department of English at the Faculty of Education, University } \\ \text { Errors, Reference } & \text { of Aden. The participants were chosen randomly to write two types of texts } \\ \text { Devices. } & \text { i.e. argumentative texts and descriptive texts. For data analysis, } \\ & \text { procedures of identifying, classifying and quantifying were used in both } \\ \text { types of texts. The results have shown that the argumentative texts included } \\ \text { more errors in the use of reference devices than descriptive texts. The } \\ \text { results also revealed that misuse of reference devices was the most } \\ \text { problematic issue in both argumentative texts and descriptive texts. }\end{array}$

\section{INTRODUCTION}

Producing a cohesive text is a very important aspect to be achieved by learners when practising the writing skill. Thus, learners are demanded to manipulate the cohesive devices to establish cohesion in their writing. However, they find it a complicated task to achieve cohesion in their written products. They encounter some difficulties in the use of cohesive ties. Such difficulties are aggregated when they are writing in an EFL context. More particularly, EFL learners face problems and commit errors in the use of referential expressions as cohesive devices when writing in English as a foreign language. Thus, errors in the use of reference ties need to be highlighted and paid the due attention since they are regarded as very contributing factors in corrupting and breaking down the relations among the parts of the text. Mainly, they are perceived as failures of producing cohesive texts. Therefore, they are worth investigation among EFL learners' writings. This study aims to provide an investigation of errors in the use of referential ties in the writings of the Yemeni learners of English as a foreign language. It is particularly conducted to provide a comparison of these errors in two text types, i.e. argumentative texts and descriptive texts. 


\section{LITERATURE REVIEW}

The use of a language in non-native context is fraught with some challenges. It is a challenging task in different practices such as translation practices due to several factors including "the linguistic and cultural differences between the source and target language" (Assaqaf, 2019:74). However, these challenges are not only confined to translation but also to other practices such as writing in L2. Similarly, writing in L2 is fraught with some challenges among which are the difficulties encountered when writing English texts cohesively.

Cohesion is a very basic feature of a well-produced text. It is realised through various processes. One of these processes is what is known in Halliday and Hasan's (1976) theory as referential cohesion. It is "a type of textual cohesion that is produced by the process of reference. It is characterized by the presence of what is known as reference words (or referring expression)" (Martin and Ringham, 2000:110). As Halliday and Hasan (1976: 308) put it, this process is created through establishing a "relation between an element of the text and something else by reference to which it is interpreted in the given instance". Therefore, the interpretation of an element by readers or hearers depends on referring to another element in the text (Johnstone, 2008:118). As Taboada (2004:160) puts it, the interpretation of reference can not be fulfilled "semantically on its own, but needs to find its resolution somewhere else". In this respect, failure of establishing such a relation results in committing errors in the use of reference ties.

Reference errors are considered as problems that learners encounter when writing in EFL contexts. Such errors involve many cases. For example, they may include cases of reference ambiguity which involve the problem of "how does the listener or reader identify which of two or more possible items in the text a reference item refers to" Halliday and Hasan (1976:310). Since these errors affect the general cohesion of the text, it is worth researching in the field of EFL writing. Some of the research attempts are sparingly summarized and provided in the ensuing lines.

In a study of the cohesive features in argumentative writing produced by Chinese undergraduates, Liu and Braine (2005) found some problems of cohesion in the students' writing. Problems in the use of reference ties were among those aspects concerned with failure of establishing grammatical cohesion. Pertaining to the use of reference ties, the findings revealed that the students appeared to face problems "of three types: the shifted use of pronouns; omission or misuse of the definite article; and underuse of comparatives and overuse of the phrase 'more and more' " (Liu and Braine, 2005: 631).

In the Yemeni context, Jibreel (2010) investigated the difficulties in using referential devices in the written discourse of the third-level students in the Department of English at the Faculty of Education, Hodeidah University. The results of the study revealed that the students can establish ties between the referential expressions and their referents in case of clear context and simple vocabulary. However, the students find it difficult to establish such ties in case of morphosyntactic, semantic and pragmatic complexities. Furthermore, the findings showed that the hierarchy of difficulty of the referential devices is comparatives, demonstratives, and personals in the same order. The findings also revealed that the use of anaphoric reference ties is more difficult than the use of cataphoric ones as diagnosed by the test but the opposite is perceived in the teachers' questionnaire.

Ong (2011) investigated cohesive errors in the expository writings of Chinese EFL learners. Using error analysis as a methodology, she found that the students committed errors in 
the different types of cohesive devices. Regarding errors of referential ties, she found that the most problematic area was found in the use of the definite article "the" as a reference tie. Learners overused and misused this article in their writings. She interpreted that as a case of lack of understanding the function of the definite article "the". The second most difficulty was found in the use of pronominal references whereas the third most difficulty was in the use of comparative references.

Yang and Sun (2012) conducted a comparative study on the use of cohesive devices in argumentative writings of thirty second-year and thirty fourth-year undergraduate Chinese EFL learners. They adopted a mixed method of quantitative and qualitative procedures for the analysis of the data. Regarding the reference errors, the findings revealed that the second-year students committed more reference errors than the fourth-year ones. As shown in the findings, errors of cohesive ties except those of conjunctions and substitution/ellipsis decreased from the second level to the fourth level. This, in turn, reflects that two years of writing experience had its effects on developing the students' discourse competence in English writing.

Crosthwaite (2013) investigated errors in the use of reference ties in an L2 narrative discourse of Mandarin and Korean learners through two corpora. Comparing the results of the two groups of learners, i.e. Mandarin and Korean learners, the study revealed that errors in the use of reference ties made by Korean L2 learners were more than those made by Mandarin ones. The findings of the study also showed that L1 background affected the frequency of errors in the use of reference ties between Mandarin and Korean L2 learners.

Abdul Rahman (2013) investigated the use of cohesive devices in the descriptive writing of Omani student-teachers. Using a quantitative research methodology, he revealed that Omani students overused certain types of cohesive devices such as repetition and reference whereas native speakers of English involved balance of the types of devices in their writing. He stated that the texts written by Omani students were difficult to understand despite the use of limited range of cohesive devices. He added that the overuse of certain types of cohesive devices led to redundancy and difficulty in understanding the texts.

Kusumaniangrum (2013) investigated the cohesive errors in the Indonesian students' argumentative writing. She applied the theoretical framework of Halliday and Hasan (1976) and the theoretical framework of error analysis. She analyzed 30 written texts qualitatively and quantitatively. The findings of the study revealed 360 cohesive errors. Errors of reference were the most frequent ones. In particular, the results showed that the most frequent errors of reference involved personal reference errors, followed by demonstrative reference errors and comparative reference errors respectively.

Regarding the present study, it is distinguished from those studies discussed above in its orientation. It is oriented towards making a comparison between errors in the use of reference ties in texts of different types. It particularly provides a comparison between errors made in argumentative texts and those errors committed in descriptive texts to the use of reference ties.

\section{DATA COLLECTION}

The data were collected in consistency with the goal of the study. Thus, the data collection reflects the nature of the research and the participants who were sampled for conducting the study.

\subsection{The Participants}

To collect the data, eighteen students $(n=18)$ of the third level in the Department of English at the Faculty of Education, Aden University were chosen randomly to constitute the 
sample of the study. The rationale behind choosing the third level students is that they have studied some courses in writing and composition in the previous levels of the B.A programme. Thus, they are expected to have some writing and composing competencies. More particularly, they are expected to have some knowledge of handling or processing cohesive devices in the process of written production.

\subsection{The Writing Tasks}

The participants were asked to write two types of texts of different topics. The first text they were asked to write was argumentative in nature on the topic of "smoking". The second text required for writing was of a descriptive nature which was about "a description of a place you have visited". The participants were given enough time for completing the writing tasks. The rationale behind these two tasks is to unfold the reference ties used in both types of texts, i.e. argumentative texts and descriptive texts.

\section{DATA ANALYSIS AND RESULTS}

To analyze the data, the first procedure was the identification and quantification of the different errors of referential ties in the two types of texts i.e. the argumentative texts and the descriptive texts. Then, the second procedure was the classification and quantification of these errors in each type of text. The third procedure was carried out to make a comparison between errors in the argumentative text and errors in the descriptive text. Thus, the first procedure was implemented for the argumentative version and the descriptive version of the texts written by each student as shown in table 1 below:

Table 1: referential errors per each student in argumentative and descriptive texts

\begin{tabular}{|c|c|c|}
\hline The students & $\begin{array}{c}\text { No. of reference errors in the } \\
\text { argumentative text }\end{array}$ & $\begin{array}{c}\text { No. of reference errors in the } \\
\text { descriptive text }\end{array}$ \\
\hline S1 & 1 & 2 \\
\hline S2 & 1 & 1 \\
\hline S3 & 4 & 1 \\
\hline S4 & - & 1 \\
\hline S5 & - & - \\
\hline S6 & - & 2 \\
\hline S7 & 3 & - \\
\hline S8 & 1 & 1 \\
\hline S9 & 5 & 1 \\
\hline S10 & - & 2 \\
\hline S11 & 4 & - \\
\hline S12 & 2 & - \\
\hline S13 & 5 & - \\
\hline S14 & 1 & 2 \\
\hline S15 & 3 & - \\
\hline S16 & 2 & 2 \\
\hline S17 & - & 18 \\
\hline S18 & - & \\
\hline Total & 32 & \\
\hline & & \\
\hline
\end{tabular}

From table 1, it can be seen that errors of reference ties in argumentative texts were committed more than those in the descriptive texts. 32 errors with a percentage of $64 \%$ out of 50 
referential errors were committed in argumentative texts whereas 18 with a percentage of $36 \%$ of the errors were found in the descriptive texts written by the students. This, in turn, indicates that argumentative writing is more difficult than descriptive writing.

After counting errors in the two types of texts, these errors were classified and quantified per each type in the two versions of the texts separately. Thus, referential errors in the argumentative texts were classified and quantified per each type as in figure 1:

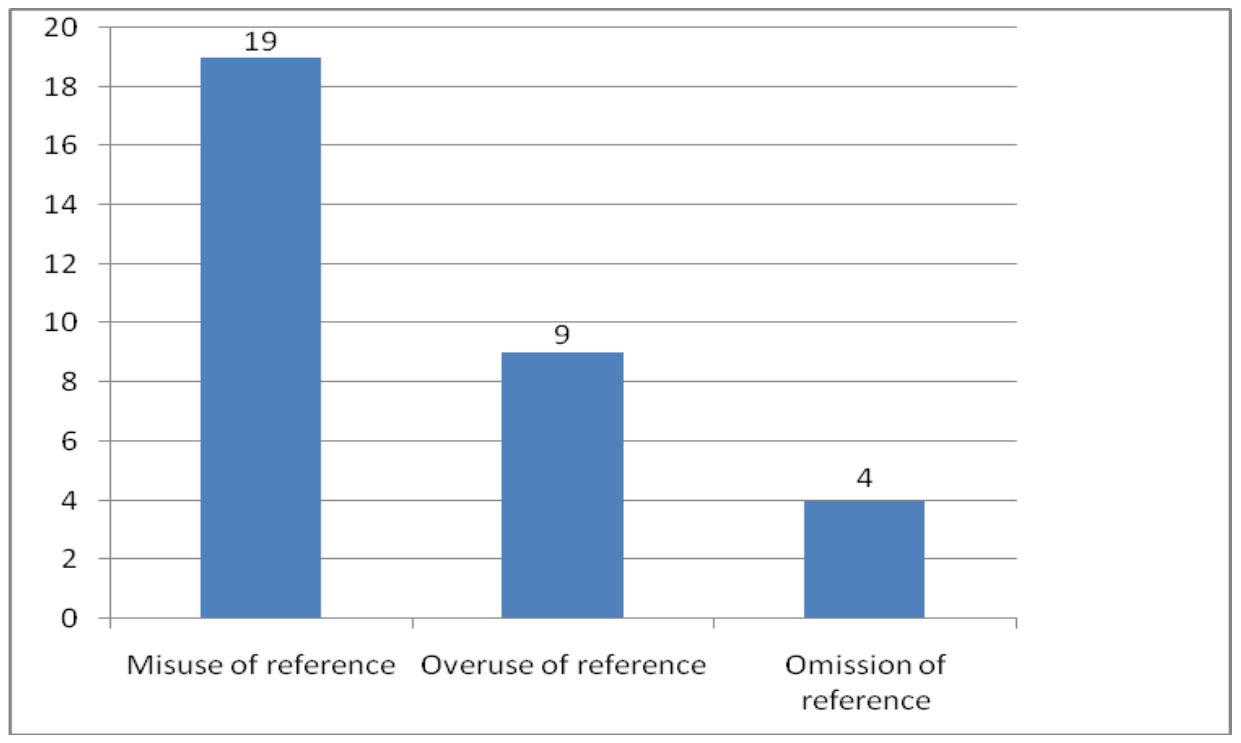

Figure 1: Errors of reference ties in argumentative texts

From figure 1, it can be seen that misuse of referential ties was the most common type of errors committed by the students in argumentative texts. Thus, they accounted for nineteen (19) out of thirty-two (32) referential errors followed by nine (9) cases of overusing referential ties and four (4) cases of reference omission respectively.

Similarly, referential errors in descriptive texts were classified and quantified per each type of errors as in figure 2:

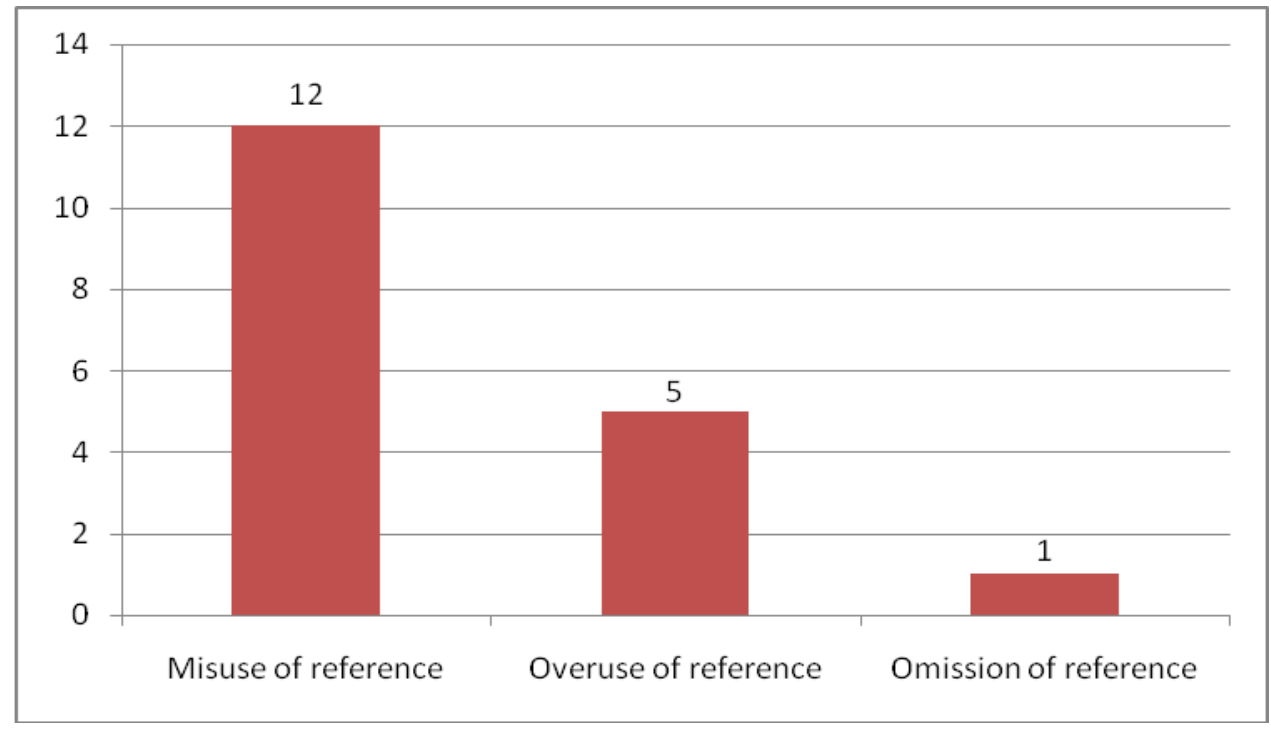

Figure 2: Errors of reference ties in descriptive texts 
From figure 2, it can be seen that misuse of referential ties was the highest rank in the descriptive texts written by the students, followed by overuse of referential ties, and omission of references respectively. Twelve (12) out of eighteen (18) cases were found to involve a misuse of reference. Five cases where found as overuse of reference whereas one case was classified as an omission of reference.

Comparing the referential errors in the two versions of the texts, it can be seen that misuse of the referential ties was the highest type of error in both versions followed by overuse of reference, and omission of reference respectively. Similarly, it can be seen in figure 1 and figure 2 that all the types of errors that have been classified in argumentative texts are more than their counterparts in the descriptive texts. To put it simply, overuse of reference in argumentative texts counted as 19 errors whereas their counterparts in descriptive texts were 12 errors. In the same way, overuse cases of referential ties in argumentative texts were 9 errors whereas 5 cases were found in descriptive texts. Regarding the omission of referential ties, 4 errors were elicited in argumentative texts whereas one case was found in the descriptive version of the texts. All in all, misusing referential ties was the most overwhelming category in both types of texts.

\section{CONCLUSIONS}

In conclusion, the use of reference ties is a tricky area. This has been shown in that most of the students have encountered problems and committed errors in this area when writing English texts.

It can also be concluded that writing argumentative texts is more complicated than writing descriptive texts in terms of using referential cohesive devices. This is clearly shown in that the students committed more reference errors in argumentative texts than in descriptive texts. This may imply that argumentative skills are very difficult to master.

Additionally, the results have shown that misuse of reference is the most problematic issue followed by overuse of reference and omission of reference respectively in both types of texts, i.e. argumentative texts and descriptive texts. This may imply that the students find it difficult to appropriately recognize the different functions of the different reference ties. This is clearly shown in that the students inappropriately used these ties without realizing their correct functions in the texts produced.

\section{REFERENCES}

Abdul Rahman, Z.A. (2013). The use of cohesive devices in descriptive writing by Omani student-teachers. SAGE Open, 3(4), 1-10.

Assaqaf, T.A.E. (2019). Techniques for interpreting English proverbs into Arabic. International Journal of Language and Literary Studies, 1(1): 73-80.

Crosthwaite, P. (2013). An error analysis of L2 English discourse reference through learner corpora analysis. Linguistic Research, 30, 163 -193.

Halliday, M.A.K and Hasan. R. (1976). Cohesion in English. London: Longman.

Jibreel, I.A.M. (2010). The use of referential devices in written discourse: An investigation of the difficulties of the students of the department of English, Faculty of Education, Hodeidah, Hodeidah University. Unpublished MA Dissertation, Aden University Yemen.

Johnstone, B. (2008). Discourse analysis (2 ${ }^{\text {nd }}$ edition). Malden, USA: Blackwell Publishing. 
Kusumaningrum, S. (2013). Error analysis on the use of cohesive devices in the students, argumentative writing. Master Thesis, Diponegoro University, Semarang, Indonesia.

Liu, M. and Braine, G. (2005). Cohesive features in argumentative writing produced by Chinese undergraduates. System, 33, 623 -636.

Martin, B. and Ringham, F. (2000). Dictionary of semiotics. London and New York. CASSEL.

Ong, J. (2011). Investigating the use of cohesive devices by Chinese EFL learners. Asian EFL Journal, 13(3), 3-65.

Taboada, M. T. (2004). Building coherence and cohesion: Task-oriented dialogue in English and Spanish. Amsterdam/Philadelphia: John Benjamins Publishing Company.

Yang, W. and Sun, Y. (2012). The use of cohesive devices in argumentative writing by Chinese EFL learners at different proficiency levels. Linguistics and Education, 23, 31-48.

\section{AUTHOR'S BIO:}

Dr. Aref Nassi Abduh Nasser is an assistant professor of English at the Faculty of Education-Lowder, University of Abyan. He has a Ph.D. in English from Dr. BAM University, Aurangabad, Maharashtra, India. He has taught courses such as Advanced Composition, Writing etc. His research interests include Error Analysis, Discourse Analysis, Composition, Academic Writing, Cohesion, and Coherence. 